\title{
O GERENCIAMENTO DO RELACIONAMENTO COM FORNECEDORES NA INTEGRAÇÃO DA CADEIA DE SUPRIMENTOS: UM ESTUDO DE CASO NA INDÚSTRIA ELETRO-MECÂNICA
}

\section{THE MANAGEMENT OF SUPPLIER RELATIONSHIP IN THE SUPPLY CHAIN MANAGEMENT(SCM): A CASE STUDY IN THE ELECTRICAL- MECHANICAL INDUSTRY}

\author{
Marly Mizue Kaibara de Almeida ${ }^{1}$; Fernando Augusto Silva Marins ${ }^{2}$; Claudemir Leif Tramarico ${ }^{3}$ \\ ${ }^{1}$ Universidade Estadual Paulista - UNESP - Guaratinguetá - Brasil \\ mkalmeida28@hotmail.com \\ ${ }^{2}$ Universidade Estadual Paulista - UNESP - Guaratinguetá - Brasil \\ fmarins@feg.unesp.br \\ ${ }^{3}$ Universidade Estadual Paulista - UNESP- Guaratinguetá - Brasil \\ claudemir.leif@terra.com.br
}

\begin{abstract}
Resumo
$O$ aumento da competição, a globalização e a necessidade de redução do ciclo de produção $e$ níveis de estoques criou a necessidade de processos baseados em alianças eficazes na cadeia de suprimentos. Estas pressões têm levado os gestores a reverem suas empresas individualmente e analisar sua posição na cadeia de suprimentos. O Gerenciamento da Cadeia de Suprimentos representa uma importante evolução nas práticas de relacionamento entre clientes e fornecedores participantes de um mesmo canal de distribuição. Este trabalho apresenta um estudo de caso em uma empresa da área elétrico-mecânica, com o objetivo de analisar como a Política de Relacionamento com Fornecedores está sendo incorporada ao seu planejamento estratégico. Constatou-se que a política adotada favoreceu a obtenção de ganhos em diversas áreas, mas que o sucesso para se atingir maior competitividade também depende dos processos internos da empresa e, principalmente, da disciplina, do treinamento das pessoas envolvidas e do alinhamento cultural das empresas parceiras na Cadeia de Suprimentos.
\end{abstract}

Palavras-chave: cadeia de suprimentos; gerenciamento; relacionamento com fornecedores; logística; produção enxuta.

\section{Introdução}

A Gestão da Cadeia de Suprimentos, ou Supply Chain Management (SCM), representa a fronteira para as empresas interessadas em obter vantagens competitivas. Consiste em uma rede de organizações ligadas por meio de diferentes processos e atividades que produzem valor na forma de produtos e serviços colocados nas mãos do consumidor final (CHRISTOPHER, 2002). Segundo a perspectiva de Ballou (2006), materiais e informações fluem em ambos os sentidos (montante ou 
jusante) na cadeia de suprimentos. O SCM integra as atividades logísticas de transportes, distribuição, armazenagem, produção e suprimentos com o objetivo de conquistar uma vantagem competitiva sustentável para todos os envolvidos na cadeia (Supply Chain - SC) em foco.

O SCM engloba o planejamento e a administração de todas as atividades envolvidas desde o fornecimento da matéria-prima, conversão, e todas as atividades de gerenciamento e administração logísticas. Ela também inclui a coordenação e colaboração entre os parceiros da cadeia, que podem ser fornecedores, intermediários, terceirizados e clientes. Em essência, o SCM busca integrar a oferta (suprimentos) com a demanda (pedidos) em todos os elos de uma SC (COUNCIL OF SUPPLY CHAIN MANAGEMENT PROFESSIONALS, 2009).

Esta integração numa SC pode se concretizar por meio de um canal de informações, que conecte todos os participantes amparados nos recursos da Tecnologia da Informação, e pelo fluxo de trocas, sustentado pelas relações chaves de negócios entre as organizações (clientes e fornecedores de vários níveis) que compõem a SC.

Segundo Lambert (2008), estas relações envolvem oito processos que, se forem bem gerenciados e integrados, aperfeiçoam o desempenho da rede de suprimentos. São eles:

- Gestão de relacionamento com clientes - responsável por estabelecer o formato ideal de relacionamento com cada tipo de cliente;

- Gestão de serviço ao cliente - responsável pelo cumprimento daquilo firmado no contrato de prestação de serviços e pelo fornecimento de informações consistentes e efetivas em termos de custos e alinhadas com a estratégia do negócio;

- Gestão de demanda - responsável por conciliar os requisitos do mercado com os recursos da cadeia de suprimento, promovendo o sincronismo entre o suprimento e a demanda;

- Atendimento do pedido - responsável por implementar uma rede logística capaz de cumprir os prazos de entregas acertados com cada cliente no contrato de prestação de serviço ao menor custo possível;

- Gestão do fluxo de manufatura - responsável por planejar e implementar processos de produção que estejam alinhados com a estratégia de negócios, com a estratégia da SC e os requisitos dos clientes incorporando a Demanda dos Fornecedores e Pesquisa \& Desenvolvimento;

- Gestão de relacionamentos com fornecedores - responsável por estabelecer os programas de parcerias e a definição das bases do contrato de prestação de serviços;

- Desenvolvimento de produtos e comercialização - responsável por incluir a opinião de fornecedores e clientes no desenvolvimento de novos produtos;

- Gestão de retornos - responsável pelas atividades de logística reversa, controle de entrada e prevenção de devoluções. 
De fato, para serem eficazes num ambiente competitivo, os elos (empresas) da SC devem integrar-se não só internamente, mas também externamente, incluindo os fornecedores e clientes, personificando o conceito de SCM (BOWERSOX e CLOSS, 2001).

Aqui se apresenta uma pesquisa exploratória e qualitativa, adotando-se o método do estudo de caso em uma empresa líder no mercado internacional de produtos da área elétrico-mecânico. $\mathrm{O}$ objetivo geral do trabalho é analisar como a Gestão de Relacionamentos com Fornecedores está sendo incorporada ao planejamento estratégico da empresa, aprimorando assim a integração da SC.

O trabalho apresenta, ainda, a evolução do relacionamento com fornecedores, desde sua importância para a implantação da mentalidade enxuta, ou Lean Thinking - LT (WOMACK E JONES, 2004) até se atingir o estágio do SCM.

O artigo está estruturado da seguinte maneira: apresenta-se na seção 2 o referencial teórico que busca caracterizar a cultura organizacional das empresas na cadeia de suprimentos e a evolução estratégica do relacionamento entre clientes e fornecedores; na seção 3 está um estudo de caso conduzido numa empresa do setor elétrico-mecânico, buscando confrontar as práticas desta empresa com os conceitos apresentados anteriormente; finalmente, as considerações finais são apresentadas, seguidas das referências utilizadas.

\section{Referencial teórico}

\subsection{A cultura organizacional das empresas na cadeia de suprimentos}

As empresas apresentam diferentes culturas organizacionais e diferentes maneiras de gerir seus negócios. Ao se integrarem não significa que houve uma incorporação cultural entre as organizações, podendo ser mantidas suas próprias culturas, estruturas e estratégias. Mas, à medida que o nível de confiança e comprometimento entre as empresas aumenta, é comum o processo de incorporação da cultura do cliente pelo fornecedor, bem como ocorrer trocas de culturas entre eles, em que se obtém uma melhor filosofia ou cultura de gerenciamento.

Uma das culturas de relevância na organização, e no SCM, é o LT (Lean Thinking), que passou a ser utilizada no método de produção Just in Time (JIT) e adotado pelos fabricantes automotivos japoneses.

Neste cenário, a Toyota Motor Company, por meio de sua liderança em termos de produtividade e qualidade, tornou-se a principal produtora de automóveis em relação às produtoras ocidentais, e difundiu o JIT para os demais países do mundo. Por ter rompido com os paradigmas, até então usuais de gerenciamento da produção, o Sistema Toyota de Produção (STP) passou a ser estudado, tornando-se uma referência mundial para as empresas de manufatura (SILVA et al, 2007). 
Segundo Womack e Jones (2003), no LT, as organizações buscam uma forma de especificar valor, realizar atividades sem interrupção e de forma eficaz, com cada vez menos esforço humano, menos equipamento, menos tempo e menos espaço físico despendidos.

Ao abordar os princípios do STP, Womack (2004) esclarece que é necessário às empresas ter a capacidade de pensar e agir globalmente. As empresas ocidentais utilizavam muitas técnicas inadequadas ao tentar implementar partes isoladas de um sistema enxuto, sem entender o todo.

O processo do LT precisava ir além das técnicas específicas e reflexões filosóficas, como as descritas por Ohno (1997), com o objetivo de reunir os métodos em um sistema completo, que até então havia ficado implícito. Como resultado final, o LT, segundo Ohno (1997) pode ser resumido em 5 princípios: determinar precisamente o valor por produto específico, identificar a cadeia de valor, fazer o valor fluir sem interrupções, deixar que o cliente estabeleça (puxe) o valor do produto e buscar a perfeição.

Ou seja, o LT busca a perfeição por meio da eliminação do desperdício, aumentando o valor do ponto de vista do cliente e melhorando a qualidade em todos os processos de negócios.

Segundo Womack e Jones (2004), a incapacidade das empresas continuarem gerando resultados a partir de produtos obtidos usando-se uma lógica aplicada para produção em massa deu origem a resultados não desejados, tais como: tempos de desenvolvimento e lançamento de produtos muito longos, cadeia logística ineficiente, tempos de fabricação excessivamente longos e perda de foco no custo, grande capacidade ociosa das empresas, requisitos dos clientes nem sempre plenamente conhecidos e atendidos, estratégias adotadas nem sempre centradas em redução de custos e aumento de taxas de retorno de investimento.

O relacionamento entre compradores e fornecedores, no LT, aborda uma perspectiva de longo prazo, em que os relacionamentos são gerenciados para evitar desperdícios e adicionar valor. Uma das principais características é a utilização de um ou dois fornecedores interdependentes, a exemplo do modelo adotado pela indústria japonesa (WOMACK e JONES, 2004). Esta tendência se acentua a medida que se busca um método de trabalho nos moldes da filosofia Just in Time.

As conquistas do sistema japonês são atribuídas às diferenças culturais, por estarem inseridos em sua cultura organizacional o respeito ao ser humano e a valorização do trabalho, que se estendem a funcionários e fornecedores. Por esta razão, quando se trata do tema "relacionamento com fornecedores" deve-se dedicar uma importância especial às práticas japonesas.

Os ocidentais não possuem esta concepção nata, tornando-se necessário entender a fundo a lógica das parcerias japonesas, pois eles são capazes de relacionar-se verdadeiramente com seus fornecedores e funcionários. A maioria dos ocidentais concorda com estes conceitos, mas a diferença é a extensão praticada pelos japoneses (DAVIS, 2001). 
Desta maneira, assim como o LT, a cultura organizacional presente na empresa cliente deve ser incorporada à empresa fornecedora, devendo ocorrer entre elas o alinhamento cultural. Portanto, as empresas participantes da cadeia devem ter a mesma mentalidade, possuindo as mesmas metas e a mesma conduta de gestão (PEREIRA e SILVA, 2009).

\subsection{A evolução estratégica do relacionamento entre clientes e fornecedores}

A relação cliente-fornecedor está em rápida e crescente evolução. Os desenvolvimentos estratégicos em curso nas indústrias estão repercutindo na relação cliente-fornecedor, em que o LT, a filosofia JIT e o SCM estão modificando o modo de operar no setor de suprimentos.

Para compreender a evolução do relacionamento cliente-fornecedor considera-se, aqui, a evolução das estratégias em andamento na indústria e as implicações na organização dos suprimentos. Primeiramente abordam-se quatro referências, definidas por Merli (1994), correspondentes a momentos importantes da história industrial, coincidentes com os seguintes tipos de empresa:

- A empresa funcional taylorista ocidental de 1950 a 1960;

- A empresa orientada para o mercado, de origem americana, de 1960 a 1970;

- A empresa japonesa de 1970 a 1980;

- A empresa de classe mundial de 1980 a 1990.

Passa-se a comentar cada um destes tipos de empresas.

\subsubsection{A empresa funcional taylorista ocidental de 1950 a 1960}

A estratégia da indústria taylorista é voltada para as operações e os princípios organizacionais do tipo mecanicista ou burocrático. A indústria funciona dentro de um esquema de forte departamentalização, ou seja, com fortes fronteiras entre as atividades dos vários departamentos, os quais buscam objetivos individuais, ainda que derivados dos objetivos globais da empresa, mas sem que se assegure uma adaptação dinâmica dos objetivos individuais à variação dos objetivos globais.

O sistema de departamentalização apresenta para os tempos de hoje uma inércia muito forte e não aceitável, traduzida em características tais como estoques altos, tempo de processamento alto e prazos de entrega não confiáveis (VOLLMANN, 2006).

A lógica do relacionamento entre cliente e fornecedor neste tipo de indústria possui as seguintes características:

- Comprar ao preço mais baixo possível e utilizar uma política de preços baseada na força contratual. Esta estratégia resulta da prioridade operacional desta empresa, que é a de perseguir a 
contínua redução de custos; o princípio fundamental é que cada fornecedor deve ser explorado ao máximo;

- É preferível ter fornecedores subordinados e controláveis, estabelecendo uma relação do tipo paternalista;

- As informações dadas ao fornecedor devem ser limitadas ao prazo de entrega e aos dados técnicos (especificações) referentes às características do produto/serviço a ser fornecido. As informações relativas às funções do produto são secundárias e opcionais;

- Não estabelecer nenhum vínculo com o fornecedor quanto a garantia de volumes, preços e continuidade de fornecimento. Isto poderia diminuir sensivelmente o poder de compra e em consequiência a pressão para reduzir os preços;

- Compra de lotes individuais, abrindo concorrências a cada compra e estimulando um número cada vez maior de fornecedores.

\subsubsection{A empresa orientada para o mercado, de origem americana dos anos 60 a 70}

A estratégia desta indústria é realizada por meio de uma contínua análise das oportunidades de negócio oferecidas pelo mercado. Iniciou-se no período entre 1960 e 1970 o desenvolvimento de um sistema de planejamento para além das fronteiras demarcadas pela departamentalização, simbolizado pela sigla MRP (Material Requirements Planning). O MRP se baseia na lista de materiais, ciclos de produção de cada item, programação mestre, níveis de inventários e no conceito de lote econômico para executar o planejamento das necessidades de materiais (AZZOLINI JR., 2001).

$\mathrm{Na}$ empresa mercadológica, os critérios que norteiam o relacionamento com os fornecedores podem ser caracterizados por:

- Ter um grande número de fornecedores alternativos;

- Estimular a concorrência para adquirir dos fornecedores materiais com preços mais baixos;

- Não oferecer garantia de fornecimentos posteriores;

- Manter relações de curta duração, onde certa rotatividade e reciclagem são consideradas saudáveis;

- Oferecer informações mínimas aos fornecedores, que se resumem em especificações técnicas, onde as funções do produto são secundárias. A adesão a estas especificações é decidida unilateralmente pelo cliente. Não se considera a tecnologia que o fornecedor poderá utilizar no seu trabalho. 


\subsubsection{A empresa japonesa dos anos 70 a 80}

Este tipo de empresa é comprometido com a melhoria do processo. A estratégia é voltada para a melhoria contínua da tecnologia e a capacidade dos processos, tendo em vista a satisfação do cliente. A qualidade é considerada prioritária para se chegar a este objetivo. Esta abordagem deu origem à organização do JIT.

Neste período houve uma reformulação da estrutura funcional do Planejamento e Controle da Produção, à medida que a tecnologia da computação avançava como o meio auxiliar à gestão de produção. O conceito de planejamento amplo foi aparecendo, passando do MRP I para o MRP II e posteriormente em 1990 para o ERP (Enterprise Resources Planning), o que configura a era dos sistemas gerenciais integrados (AZZOLINI JR., 2001).

As características da relação cliente-fornecedor na indústria japonesa são descritas a seguir:

- Descentralizar o máximo volume possível de produção de partes/itens ou mesmo a inteira responsabilidade do projeto e da produção;

- Criar uma forte relação com um número limitado de fornecedores;

- Pesquisa da economia de compra em longo prazo. O ponto de vista não é o de avaliar algumas ofertas alternativas para cada novo componente, mas sim o de escolher o fornecedor com quem investir no estudo e na produção de um novo componente. A avaliação é feita sobre os custos totais;

- Comakership operacional. Corresponde a parceria da empresa com seu fornecedor a nível operacional. A filosofia que rege os relacionamentos operacionais no modelo Comakership é derivada da lógica das abordagens Qualidade Total e JIT. O fornecedor é praticamente um setor da empresa. Há uma forte integração dos sistemas administrativos e operacionais;

- As relações são em longo prazo;

- Os fornecimentos são efetuados, segundo a filosofia JIT e a produção é puxada e sincronizada com as necessidades do cliente.

\subsubsection{A empresa de classe mundial dos anos 80 e 90}

As empresas são do tipo mundial, pois não faz mais sentido falar em áreas geográficas, mesmo porque as maiores empresas estão presentes no mundo inteiro. As empresas de classe mundial representam a síntese das duas culturas industriais, a ocidental (orientada para o mercado) e a japonesa (orientada para as operações), sendo a soma do que cada uma tem de melhor. A estratégia desta indústria é a busca da satisfação do cliente, e não a sua exploração a curto prazo, para garantir um faturamento sólido e bons resultados a médio-longo prazos. 
Neste período verifica-se a ocorrência do avanço da Tecnologia de Informação (TI) e a grande concorrência causada pela globalização. Há uma necessidade das empresas terem informações rápidas e precisas para a tomada de decisões em tempo hábil e melhor eficiência no atendimento a seus clientes.

$\mathrm{Na}$ lógica do relacionamento com os fornecedores se destacam:

- Relacionamento em longo prazo, parceria no negócio e poucos fornecedores de confiança;

- Empresas integradas operacionalmente e nas ações de desenvolvimento e industrialização dos componentes e tecnologias;

- Rede de informação comum, utilizada para procedimentos operacionais (entregas, faturamento), seja para funções administrativas (programação, administração de mudanças, etc.).

Dentre a evolução estratégia do relacionamento entre clientes e fornecedores, encontra-se o modelo de SCM. Este modelo agrega as estratégias do LT e do JIT, ressaltando a necessidade da integração entre todos os membros envolvidos numa SC e o aprimoramento da relação clientefornecedor.

\subsubsection{Logística e SCM}

Desde meados do período entre 1980 e 1990, muito se tem falado e escrito sobre um tema que também caracteriza uma grande evolução para o mundo dos negócios, se apresentando como um novo modelo competitivo e gerencial às empresas, o SCM.

De fato, segundo Fernandes (2008), o SCM revolucionou as estratégias e a maneira de pensar de muitos gestores envolvidos na administração de suprimentos e relacionamento com fornecedores e clientes, porém o tema ainda é motivo de grandes conflitos dentro das empresas, que começam a adotá-lo efetivamente na prática.

Para Fleury et al (2000), o SCM é a vertente mais rica do pensamento logístico e está relacionado ao esforço de coordenação dos canais de distribuição por meio da integração de processos de negócios que interligam seus diversos participantes.

De acordo com Robeson e Copacino (1994), o SCM foi originalmente discutido num contexto logístico de gerenciamento de inventário através de toda a cadeia. A idéia era lidar com o inventário da maneira mais eficiente possível, fazendo com que os estoques dos vários membros pertencentes à cadeia não fossem redundantes entre si, diminuindo o custo total ao longo da cadeia.

A aplicação do SCM foi ampliada para um contexto de gerenciamento global do sistema de suprimento, abordando funções como compras, produção, distribuição e marketing. Seu princípio básico constitui em integrar as informações entre fornecedores, indústria, distribuidores, varejistas, 
atacadistas e consumidores finais, de forma a ordenar, racionalizar e otimizar a produção e o escoamento dos produtos.

Dentre as principais práticas e iniciativas utilizadas na gestão colaborativa da SC, segundo Pires (2004) e Wanke (2004), destacam-se:

- Desenvolvimento de fornecedores: pode variar de uma avaliação informal das operações de produção até a criação de um programa de investimentos conjunto em treinamento, melhorias de produto e processos, entre outros;

- Outsourcing (terceirização): prática em que parte dos produtos e serviços utilizados em uma empresa é providenciada por outra empresa externa de forma colaborativa e independente. A empresa fornecedora desenvolve e continuamente melhora a competência e a infra-estrutura para atender o cliente e este continua mantendo uma estreita e colaborativa integração com o fornecedor;

- In plant representatives (Residentes): caracteriza-se pela presença de representantes de determinadas empresas trabalhando em tempo integral em seus fornecedores, criando uma comunicação dinâmica e mais confiável entre as empresas envolvidas;

- Early Supplier Involvement (ESI, Envolvimento dos Fornecedores desde a Fase Inicial do projeto do produto): o fornecedor traz sua competência e conhecimentos para a criação de um produto de forma mais rápida, ao menor custo e maior qualidade;

- Milk Run (Coleta Programada de Peças): a lógica é ter um sistema de abastecimento com roteiros e horários predefinidos para as coletas de materiais junto aos fornecedores. O objetivo principal é reduzir os custos logísticos de abastecimento via economias de escala e racionalização das rotas, bem como aumentar a confiabilidade do processo como um todo;

- Vendor Managed Inventory (VMI, Estoque Gerenciado pelo Fornecedor): o fornecedor se responsabiliza por gerenciar seu estoque no cliente, incluindo o processo de reposição;

- Quick Response (QR, Resposta Rápida): os fornecedores recebem os dados coletados nos pontos de venda no cliente e utilizam essa informação para sincronizar suas operações de produção e seus estoques com as vendas reais.

\section{Estudo de caso}

\subsection{Método e instrumentos de pesquisa}

A necessidade de se formar novos arranjos com foco na eficiência coletiva induziu as organizações a uma inter-relação que requereu novos padrões de cooperação, compartilhamento de informações e competição entre eles (QUEIROZ; PINTO; PEREIRA, 2009). Segundo Castells (2006) as redes de relacionamento oferecem pouco espaço para as ações individuais e o foco nos 
relacionamentos é a eficiência coletiva. A SCM marcou uma evolução dos sistemas de gerenciamento do negócio que transcende as fronteiras da empresa e passa a abordar a cadeia como um todo (QUEIROZ; PINTO; PEREIRA, 2009).

Dentro deste contexto se encontra o processo de gestão de relacionamento com fornecedores, que se constitui no foco deste trabalho. A tarefa de desenvolvimento de fornecedores adquiriu uma dimensão estratégica, cujo objetivo é dar orientação e suporte à área de suprimentos, mediante a avaliação e seleção de fontes potenciais de fornecimento, com o propósito de assegurar a conquista e manutenção da competitividade das empresas.

Assim, pode-se entender a gestão do relacionamento com fornecedores como sendo uma estratégia alicerçada no desenvolvimento de parcerias de longo prazo, em ferramentas de tecnologia de informação e nos processos internos simples e eficazes (MERLI, 1994).

Para se comprovar a eficiência atingida pelo gerenciamento das relações com fornecedores, este artigo apresenta a incorporação de uma estratégia prática adotada por uma empresa brasileira da área eletro-mecânico, atualmente controlada por um grupo americano, líder mundial na fabricação na modalidade de seus produtos. A análise da eficiência da implementação da Gestão de Relacionamento com Fornecedores abrangeu o período de 1993 - quando foi criado o setor de logística na empresa pesquisada - até 2009.

Desta maneira, dentre as abordagens de pesquisa optou-se pelo estudo de caso único que permite o aprofundamento na investigação e que, segundo Miguel (2009), é o mais indicado para pesquisas que envolvem profundidade e amplitude.

Este tipo de abordagem se constitui, de acordo com Miguel (2009), num estudo de natureza empírica que investiga um determinado fenômeno, geralmente contemporâneo, dentro de um contexto real de vida, quando as fronteiras entre o fenômeno e o contexto não são claramente definidas. O objetivo é esclarecer o motivo pelo qual um conjunto de decisões foi tomado, como elas foram implementadas e quais os resultados alcançados.

Aqui, como o estudo de caso foi efetuado em uma empresa líder no mercado mundial do setor eletro-mecânico as conclusões desta pesquisa podem ser generalizadas para outras indústrias deste setor. Além disto, o estudo de caso permite a adição de casos posteriores, fazendo com que a validação deste trabalho possa ser ratificada no futuro.

O método utilizado na pesquisa para construção das observações e conclusões, representado pela Figura 1, baseou-se em:

- Entrevistas com profissionais ligados à área de compras (chefe de compras), área de fundição e usinagem (coordenador das áreas) e por meio de um questionário enviado às áreas de gestão de logística da empresa, gestão de lean manufacturing e gestão de qualidade de fornecedores 
envolvidos em projetos de melhorias da qualidade de fornecimentos e do desempenho logístico. Além disto, utilizou-se dados e informações advindas de materiais fornecidos pela empresa.

- Avaliação do desafio proposto pela incorporação da estratégia e da implementação dos projetos;

- Relação entre a avaliação dos projetos e os problemas encontrados;

- Conclusão e análise dos resultados.

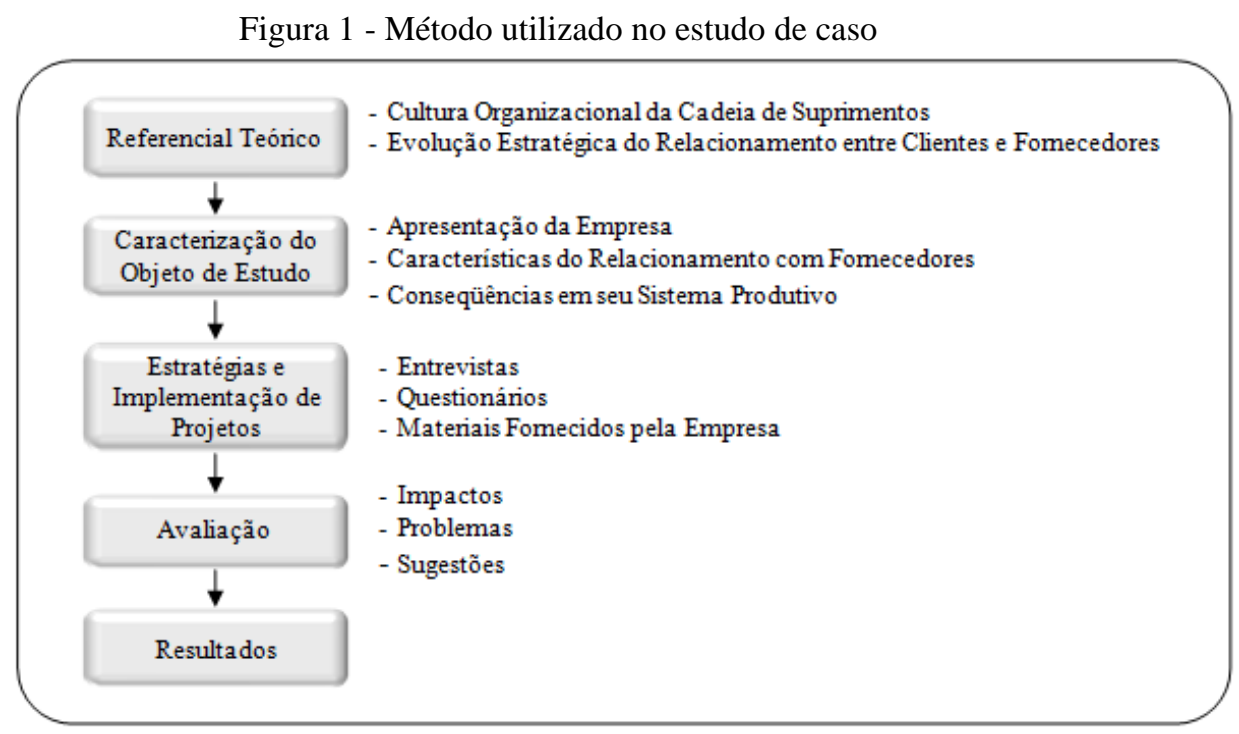

Fonte: Adaptado de Miguel (2009)

\subsection{Caracterização do objeto de estudo}

Esta parte do trabalho objetiva apresentar a empresa na qual foi desenvolvido o estudo de caso, bem como a forma como ela vem desenvolvendo o tratamento com seus fornecedores e as conseqüências em seu sistema produtivo.

A empresa em questão tem uma participação aproximada de $20 \%$ no mercado mundial, constituindo-se o líder na fabricação de produtos em sua área, sendo que 70\% de suas vendas estão voltadas para o mercado externo e $30 \%$ para o mercado interno, com uma capacidade produtiva de 30 milhões de produtos ao ano.

O setor de logística na empresa foi criado em 1993. Estavam subordinados à Diretoria de Logística, o Departamento de Distribuição Física e Operacional, o Departamento de Programação, Controle e Produção de Materiais, a Divisão de Fundição, e a Divisão de Suprimentos. Por sua vez estavam subordinados à Divisão de Suprimentos, o Departamento de Compras de Materiais Indiretos e Ativos, Compras de Materiais Diretos e Compras no Exterior. A Figura 2 mostra o organograma da empresa. 
Figura 2 - Organograma da empresa

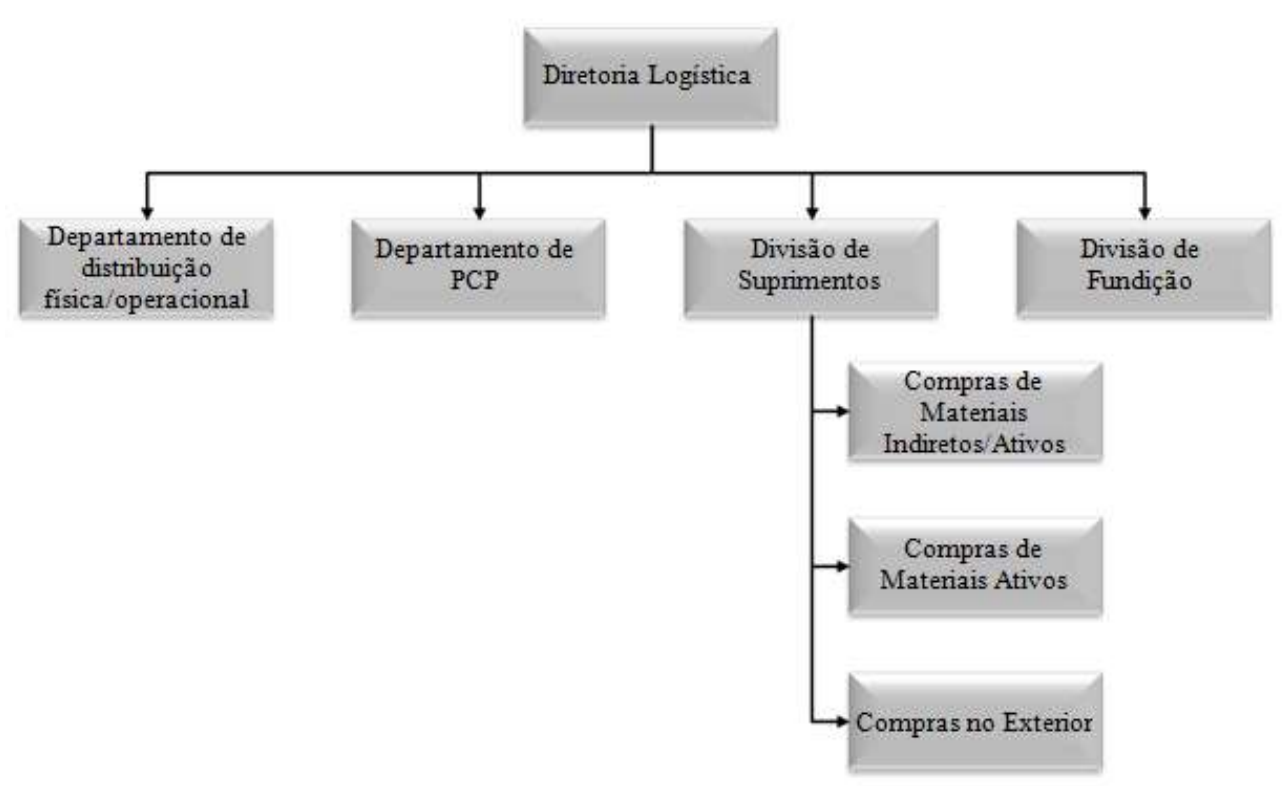

Fonte: Divisão de suprimentos da empresa (1996)

O Planejamento e o Controle da Produção eram feitos com base na previsão de vendas e, conseqüentemente, também eram efetuados o planejamento e o controle de materiais, envolvendo o estoque de componentes por meio de uma micro-programação, ou seja, o Planejamento das Necessidades de Materiais, ou Material Requirements Planning (MRP), que permitia determinar a quantidade e o momento em que eram necessários os materiais, no processo de manufatura. Com isto buscava-se cumprir os programas de entrega dos produtos com um mínimo de formação de estoques.

A próxima etapa era a armazenagem dos insumos nos depósitos onde se dava a movimentação dos materiais, que por sua vez eram utilizados na fabricação dos produtos. Estavam ligados neste processo a engenharia de produtos, a área de suprimentos e ainda a engenharia industrial, custos e o departamento de garantia da qualidade dos fornecedores, como ilustra a Figura 3.

Figura 3 - Maxofluxograma do departamento de planejamento e controle da produção

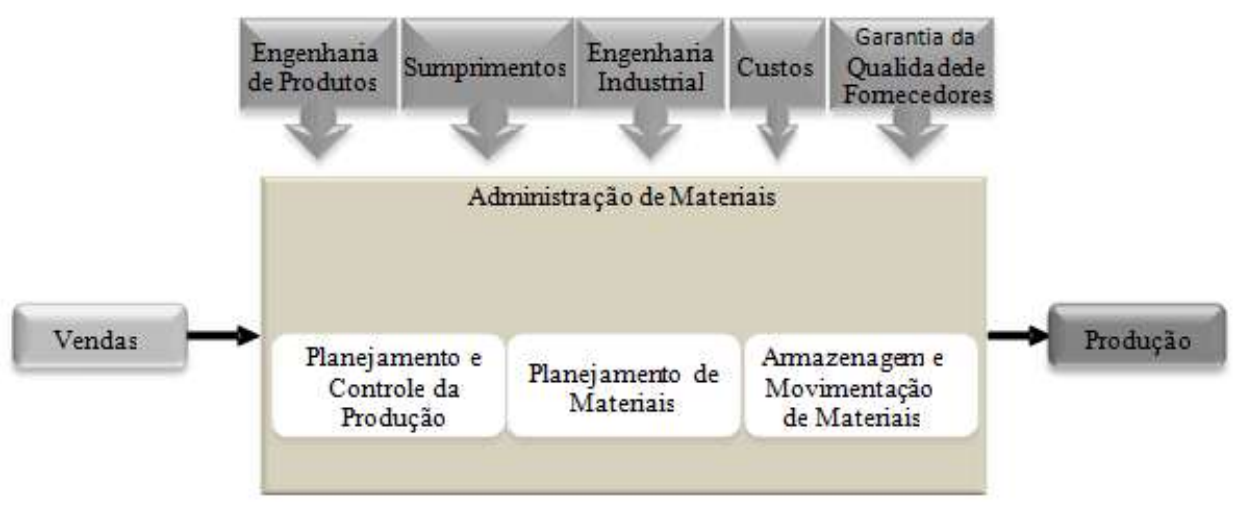

Fonte: Divisão de suprimentos da empresa (1996) 
Atualmente, não existe uma Diretoria de Logística, mas uma diretoria de SC, da qual a Logística faz parte. O time de logística não tem ação sobre a contratação logística, mas sobre a sua operação, conforme ilustra a Figura 4 isto envolve: almoxarifados, importação, exportação e transporte interno (inbound) e externo (outbound).

Figura 4 - Áreas de atuação da logística na empresa

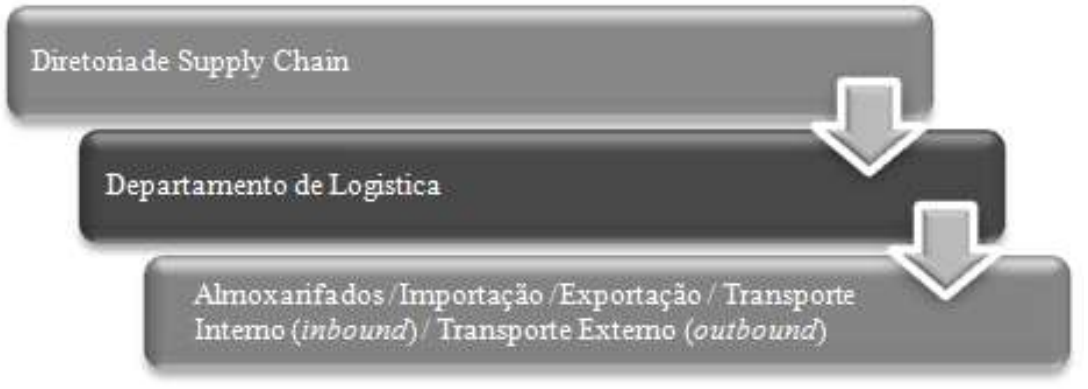

Fonte: Empresa estudada (2010)

\subsubsection{O Programa da qualidade de fornecedores}

Para a empresa em questão, a manutenção de sua competitividade não poderia ser efetuada de forma isolada, isto é, ela dependia de uma cadeia de fornecedores e clientes, que deveriam ter como objetivo superar as expectativas do consumidor final.

Sob este ponto de vista, o fornecedor era parte integrante do processo produtivo e, portanto, era fundamental a tomada de posição frente aos objetivos da empresa, que era trabalhar com base nos princípios do LT e beneficiar o consumidor final. As relações com os fornecedores representavam um fator fundamental e determinante.

Com o intuito de estabelecer diretrizes e orientar o relacionamento entre a empresa e seus fornecedores, foi criado em 1997 o Programa da Qualidade de Fornecedores - PQF, que visava estabelecer um quadro de fornecedores que atuassem como parceiros, num relacionamento estável e duradouro, baseado em confiança mútua.

Por meio do PQF efetuavam-se a avaliação, o incentivo, a orientação e o acompanhamento contínuo dos fornecedores, que se dedicassem, se empenhassem e participassem ativamente do processo de melhoria contínua, atendendo ou superando as expectativas da empresa.

Desde 1997, a área de produção realizava com a área de suprimentos, reuniões mensais. Procurava-se também contato mensal no mínimo com a fundição, levantando problemas ocorridos no mês anterior sistematicamente objetivando soluções para os problemas não ocorrerem novamente. Uma vez a cada dois meses, havia o contato com a área de suprimentos sendo convidados alguns dos fornecedores mais críticos (aqueles que apresentavam desvios na qualidade dos produtos e serviços) daquele mês.

Atualmente este programa continua em uso, tendo sido submetido a diversos aperfeiçoamentos, sempre no intuito de melhorar a qualidade dos insumos fornecidos, através de 
ações de prevenção de falhas. Novas ferramentas para a seleção de novos fornecedores, para certificação de novos itens em desenvolvimento e para o monitoramento e avaliação do desempenho dos fornecedores foram desenvolvidos e implementados.

A estrutura organizacional e de responsabilidades na empresa sofreram substanciais modificações, incluindo a forma e freqüência de relacionamentos entre as áreas. Atualmente a qualidade de fornecedores é administrada por área específica, integrada à estrutura de Logística, e contatos com os fornecedores são realizados semanalmente através de agenda fixa, onde assuntos relacionados à qualidade e outros são informados e debatidos. Desta forma, pode-se afirmar que houve alterações nos procedimentos, tornando o contato entre as áreas mais freqüente e mais eficaz.

Os fornecedores quando causadores de anomalias de qualidade são obrigados a reportar suas causas fundamentais e ações corretivas/preventivas, segundo modelo padronizado, e dependendo da situação continuam a serem convidados a comparecer à empresa para apresentar formalmente o processo de ação corretiva.

No LT o relacionamento entre compradores e fornecedores aborda uma perspectiva de longo prazo, em que os relacionamentos são gerenciados para evitar desperdícios e adicionar valor. No SCM, que se apresenta como um novo modelo competitivo para as empresas, utilizam-se práticas e iniciativas de gestão colaborativa da cadeia de suprimentos.

Dentre as práticas rotineiras na empresa em foco destacam-se:

- Desenvolvimento de fornecedores: dependendo da situação, e com base em análise crítica da necessidade, pode-se selecionar um novo fornecedor, realizando-se uma avaliação em profundidade em seu sistema da qualidade ou, alternativamente, qualquer avaliação pode ser dispensada, dependendo das certificações apresentadas e da reputação do fornecedor no mercado;

- In Plant Representatives (residentes): há três casos de fornecedores que mantêm representantes (técnicos residentes), por solicitação da empresa;

- Early Supplier Involvement (ESI): sempre que viável, a participação de fornecedores é solicitada e estimulada, havendo, em certos casos, o estabelecimento de acordos de sigilo ("NonDisclosure Agreement"). Estes acordos, ou Termos de Confidencialidade correspondem a uma relação especial de confidencialidade entre as entidades jurídicas ou físicas, visando a proteção de informações e fixando parâmetros de sua utilização e conseqüências patrimoniais oriundas de sua quebra.

\subsubsection{O desenvolvimento da filosofia JIT e a filosofia LT na empresa}

Para manter sua competitividade e se tornar a líder o mercado mundial, adotando práticas da mais moderna forma de gerenciamento de uma empresa, ou seja, o SCM, a empresa pesquisada fez 
uso dos instrumentos da filosofia JIT e o LT para chegar ao grau de amadurecimento em que se encontra.

Dentre estes instrumentos está o relacionamento com os fornecedores, que se constituiu num fator fundamental para o sucesso da produção enxuta, que envolveu os cumprimentos de prazos de entrega e da garantia de qualidade do material. Um dos resultados mais significativos da área de compras foi a abertura para negociações com fornecedores, obtida pela confiança e comprometimento de ambas as partes, trazendo vantagens de custo, qualidade e busca de melhorias desejadas, para ambas as partes.

O projeto da implementação do programa JIT na empresa iniciou-se em agosto de 1997. Desenvolveu-se um "piloto" com os setores de usinagem e fundição da empresa. Estes setores foram priorizados devido ao fato de que os componentes fundidos representavam uma significativa parcela nos custos da matéria-prima utilizada nos produtos fabricados, desta forma a integração vertical (fundição), viabilizava condições de maior competitividade.

A usinagem dos componentes fundidos e sinterizados, se constituíam em um dos processos no qual poder-se-ia obter vantagens competitivas de custos, advindos da elevada produtividade, bem como do controle sobre os característicos críticos que viabilizavam o elevado nível de qualidade (confiabilidade e desempenho) dos produtos produzidos.

Constatou-se os seguintes ganhos em relação a este empreendimento:

- Melhoria na parte de transporte que passou a ter um melhor sincronismo;

- Eliminação dos estoques com a liberação do espaço físico para aumentar a área de produção introduzindo novas máquinas, aumentando a produtividade;

- O trabalho em células de manufatura proporcionou um maior rendimento do que trabalhar de forma individualizada e permitiu aumentar a interação entre as pessoas, voltados para um mesmo objetivo a ser implementado;

- Diminuição dos lotes;

- Melhor lead-time produtivo;

- Melhor nível de qualidade do material de fornecedores utilizados na produção.

Apesar dos ganhos obtidos, vários fatores foram fundamentais para que a filosofia JIT não obtivesse êxito em sua plenitude: existência de gargalos, aumento do estoque em processo, maior frequiência de paradas na produção, disciplina, terceirização da logística, cultura, treinamento entre outros.

O aprendizado possibilitou a reflexão e a migração para a implementação da Filosofia LT na empresa, em 2006. Atualmente o LT está sendo aplicado em todas as plantas da empresa. Sua aplicação na SC está em fase inicial, adotando-se as análises de fluxo de valor para se identificar e 
remover os desperdícios, de forma a criar um fluxo contínuo puxado (por meio de kanbans) e assim viabilizar a redução dos estoques de matérias-primas e componentes, tanto nos fornecedores como na própria empresa.

\subsubsection{Análise de resultados}

Conforme comentado a Filosofia JIT não obteve êxito em sua plenitude na empresa, mas um dos fatores importantes advindos desta filosofia foi a aproximação dos fornecedores. Isto possibilitou uma análise crítica da SC, atingindo uma evolução significativa em termos de qualidade, diminuição de estoques, aumento da expansão da produção sem ter que investir em espaço, com ganhos em custo por meio de parcerias, programas e acordos comerciais de qualidade assegurada.

As situações de desabastecimento, em que a matéria-prima requisitada não estava disponível, vêm sendo resolvidas com base na busca do aprimoramento de técnicas de previsão de demanda e a integração com o setor de compras, além das técnicas discutidas anteriormente, como o Desenvolvimento de Fornecedores, In Plant Representatives (residentes) e o ESI. Pode-se afirmar que houve alterações nos procedimentos, tornando o contato entre as áreas mais freqüente e mais eficaz.

A empresa contava com um fornecedores de 130 ativos para materiais diretos e a estratégia era manter duas fontes (dual sourcing) para as principais categorias, como ilustra o Gráfico 1.

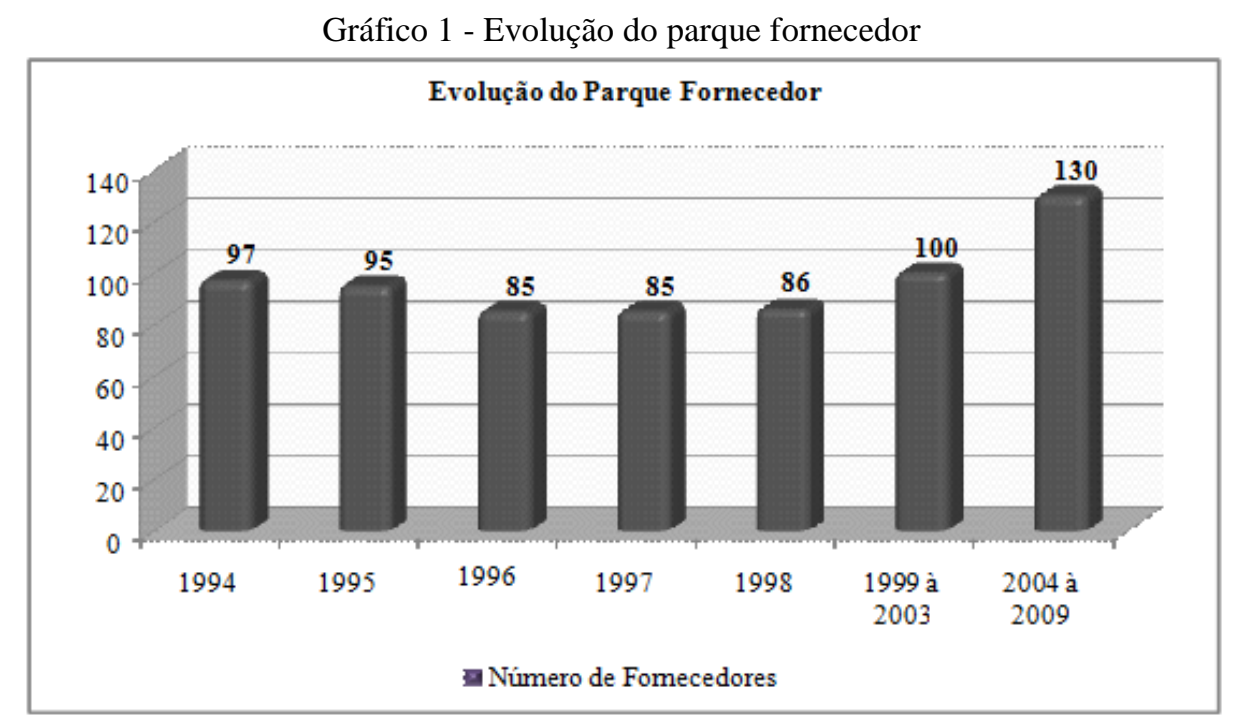

Fonte: Empresa estudada (2010)

Comparando-se os anos de 1994 a 2009, verifica-se que o número de fornecedores aumentou 34\%. De 1994 a 1998 o número de fornecedores esteve na faixa entre 86 e 97, de 1999 a 2003 ficou em torno de aproximadamente 100 e, em 2009, a empresa contava com cerca de 130 fornecedores. 
O objetivo da empresa era garantir a sustentabilidade da cadeia de fornecedores estabelecendo contratos de médio e longo prazo.

A empresa trabalhava com os 130 fornecedores regulares de matérias-primas e componentes, sendo ao pelo menos 1 fornecimento a cada 6 meses. Não foi fixada uma meta para diminuir o número de fornecedores, mas o que se observou foi a busca contínua de oportunidades de negócios com novos fornecedores em países de baixo custo, haja vista a necessidade da empresa em baixar seus custos de produção e permanecer competitiva em preços. Com isto, aumentou-se o risco para a qualidade, pois foram introduzidas maior variabilidade nos processos por meio das matérias-primas e componentes fornecidos.

Procurou-se dimensionar e limitar tais riscos por meio do uso de ferramentas adequadas nas fases de identificação de fornecedores, certificação e monitoramento da sua qualidade. Além disto, a oportunidade de novos negócios e a preferência pelo fornecimento eram normalmente dadas aos fornecedores atuais, desde que competitivos em relação às alternativas identificadas.

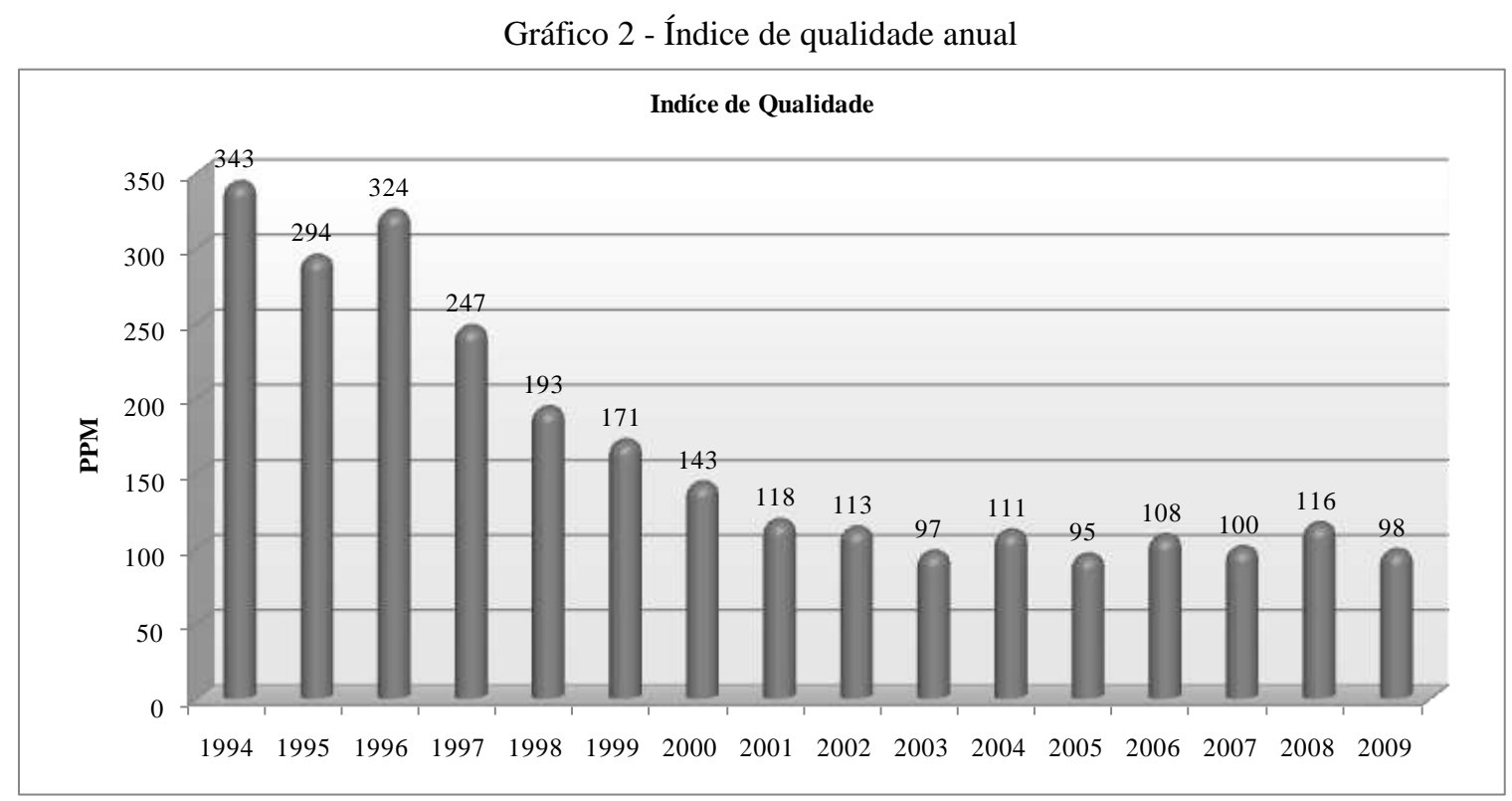

Fonte: Empresa estudada (2010)

O índice da qualidade evoluiu satisfatoriamente ao longo dos anos como mostrado no Gráfico 2 e teve por base a observação dos defeitos das peças defeituosas por milhão. Observa-se que ganhos significativos até 2009. Entre 1994 a 2009 os ganhos em qualidade foram na ordem de 71\%, pois o número de peças defeituosas por milhão em 1994 girava em torno de 343 e em 2009 este número baixou para 98 peças.

Como os ganhos de qualidade estão intrinsecamente ligados a certificação de fornecedores, testou-se a existência de correlação ao nível de significância $1 \%$ entre o índice de qualidade e o número de fornecedores certificados conforme resultado apresentado na Tabela 1. 
Tabela 1: Correlação entre índice de qualidade e número de fornecedores certificados

\begin{tabular}{|c|c|c|c|c|}
\hline \multirow[b]{2}{*}{ Objeto } & \multicolumn{2}{|c|}{ Teste $\mathrm{t}$} & \multirow[b]{2}{*}{$\mathrm{r}^{2}$} & \multirow[b]{2}{*}{ Conclusão } \\
\hline & $\begin{array}{l}\text { Valor } \\
\text { Crítico }\end{array}$ & $\begin{array}{c}\text { Valor } \\
\text { Calculado }\end{array}$ & & \\
\hline $\begin{array}{l}\text { Índice de qualidade e número } \\
\text { de fornecedores certificados }\end{array}$ & 2,977 & 9,682 & $87 \%$ & $\begin{array}{l}\text { Existência de correlação ao nível de } \\
\text { significância } 1 \% \text { e com } \mathrm{r}^{2}=87 \% \text { explica } \\
\text { estatísticamente a correlação. }\end{array}$ \\
\hline
\end{tabular}

Fonte: Autoria própria (2011)

A adoção dos instrumentos da filosofia JIT na empresa e o LT possibilitaram os ganhos em qualidade por meio das parcerias, programas e acordos comerciais de qualidade assegurada. Atualmente $95 \%$ dos fornecedores regulares têm seus sistemas da qualidade certificados (ISO 9001 ou ISO/TSI 6949), como mostrado no Gráfico 3.

Gráfico 3 - Certificação de fornecedores

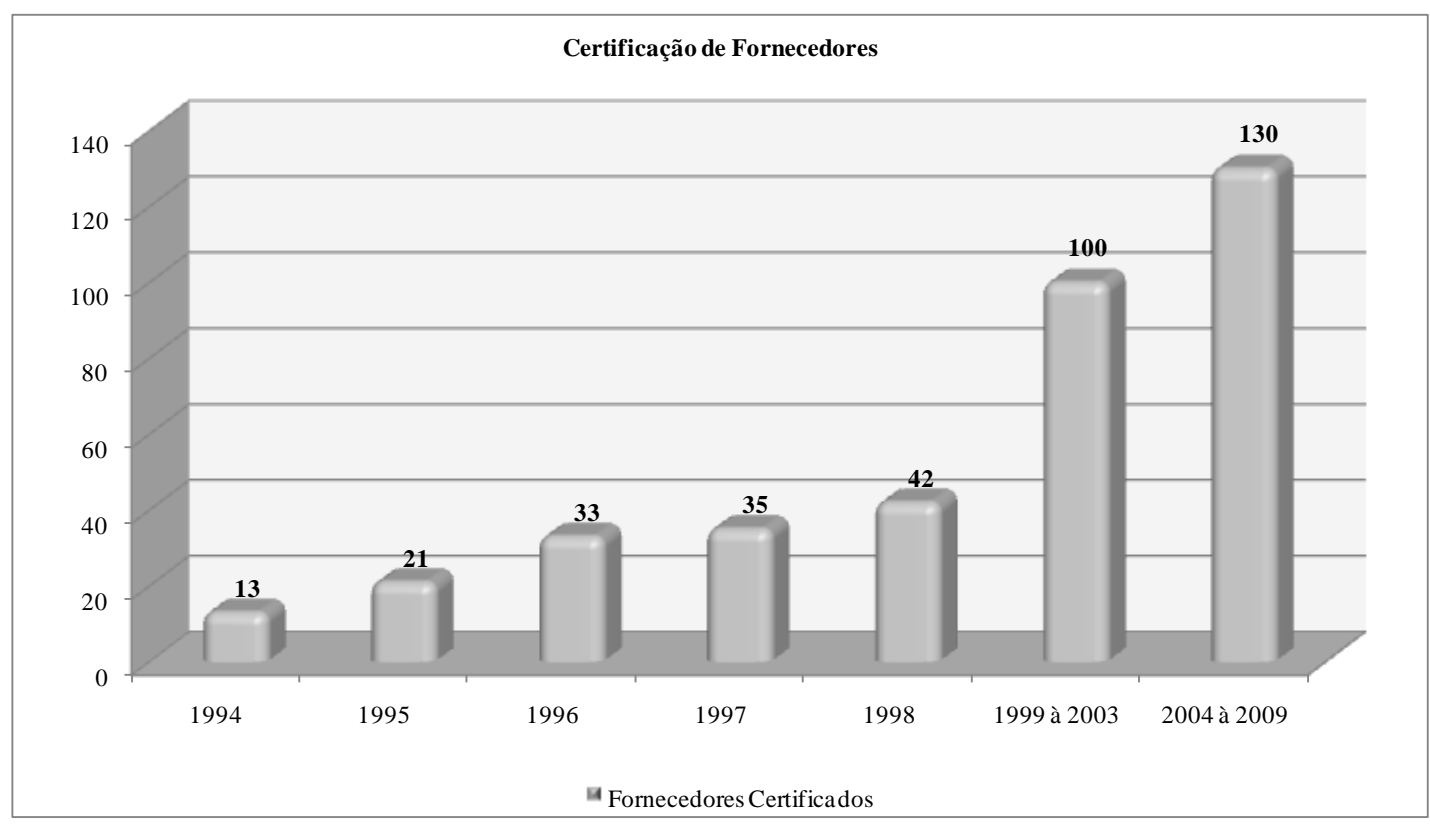

Fonte: Empresa estudada (2010)

Os fornecedores da empresa obtiveram um ganho positivo em termos de certificação. Mas, sabe-se que o fato de um fornecedor obter uma certificação de seu sistema da qualidade não assegura um bom desempenho da qualidade dos seus produtos. Não são somente matériasprimas/componentes que causam desvios de qualidade no produto, mas, também, e principalmente, os processos internos na empresa.

Os problemas de qualidade de fornecedores vêm sendo tratados por meio de ferramentas de prevenção (certificação de novos itens/auditorias do processo de fornecedores) e correção de falhas (processo de ação corretiva/tratamento de anomalias), onde metas são definidas e profissionais capacitados dedicam-se a estas atividades, sempre buscando a melhoria dos processos de 
manufatura e questionamento permanente dos projetos/especificações dos itens a serem certificados e comprados.

Para melhorar esta análise optou-se por verificar se as variáveis índice de qualidade, número de fornecedores e números de fornecedores certificados seriam ou não independentes. O resultado do teste, que mostrou a não independência entre as variáveis, está na Tabela 2.

Tabela 2 - Resultado do teste de independência

\begin{tabular}{|l|c|c|c|}
\hline \multirow{2}{*}{ Objeto } & \multicolumn{2}{|c|}{ Teste de independência } & \multirow{2}{*}{ Conclusão } \\
\cline { 2 - 3 } & $\begin{array}{l}\text { Chi-quadrado } \\
\text { Valor Crítico }\end{array}$ & $\begin{array}{c}\text { Chi-quadrado } \\
\text { Valor Calculado }\end{array}$ & \\
\hline $\begin{array}{l}\text { Índice de qualidade, número } \\
\text { de fornecedores e número de } \\
\text { fornecedores qualificadas }\end{array}$ & 50,892 & 29,185 & $\begin{array}{l}\text { Ao nível de 1\% significância o resultado } \\
\text { expressa que as variáveis não são } \\
\text { independentes. }\end{array}$ \\
\hline
\end{tabular}

Fonte: Autoria própria (2011)

\section{Conclusões}

O objetivo deste trabalho foi analisar, por meio de um estudo de caso, como a política de Relacionamento com Fornecedores, considerando as estratégias em andamento nas indústrias e suas implicações na organização dos suprimentos, vem sendo incorporada no planejamento estratégico de uma empresa brasileira líder mundial do setor elétrico-mecânico.

A pesquisa identificou que a política adotada pela empresa favoreceu ganhos em diversos aspectos como a qualidade do produto, custos e produtividade, entre outros. Entretanto, os fornecedores certificados, ou seja, aqueles que possuem uma certificação de seu sistema da qualidade não asseguraram um bom desempenho da qualidade dos seus produtos. As matériasprimas e componentes não são os únicos elementos que causam desvios de qualidade dos produtos, mas principalmente os processos internos da empresa.

Neste sentido, a empresa está adotando práticas do LT em todas as suas plantas, com análises de fluxo de valor para identificar desperdícios e criar desta forma um fluxo contínuo (por meio de kanbans) e assim viabilizar a redução dos estoques de matéria-prima e componentes tanto nos fornecedores como na empresa.

Práticas e iniciativas utilizadas na gestão colaborativa da SC também vêm sendo adotadas, como Desenvolvimento de Fornecedores, In Plant Representatives (residentes) e Early Supplier Involvement, no intuito de vincular a estratégia de relacionamento com fornecedores a procedimentos da gestão da cadeia de suprimentos como um todo, visando a satisfação do cliente final. 
Como resultado importante da pesquisa, pode-se ressaltar que o processo de Gestão de Relacionamento com Fornecedores se constitui num importante processo da SC, que deve ser bem gerenciado para se obter resultados melhores. A implementação deste processo não é tarefa fácil, pois as práticas do relacionamento com fornecedores devem estar atreladas aos procedimentos do SCM e estar, também, vinculadas aos processos internos da empresa.

Verificou-se a existência de forte correlação e dependência entre o número de fornecedores certificados e o nível de qualidade atingidos pela empresa. Esta dependência foi demonstrada pelo teste que resultou no valor de $\mathrm{r}^{2}=87 \%$, explicando estatisticamente a correlação.

Para que as estratégias tenham êxito, são imprescindíveis fatores como disciplina, treinamento de toda a equipe envolvida e alinhamento cultural para que as empresas participantes da cadeia tenham a mesma mentalidade, com as mesmas metas e mesma conduta de gestão. Estes fatores se constituem nos principais aspectos a serem monitorados numa Gestão de Relacionamento com Fornecedores, pois afetam as estratégias e os processos e, para que as metas sejam atingidas e a satisfação do cliente seja garantida, é necessário o comprometimento de toda a equipe envolvida.

\begin{abstract}
The Supply Chain Management (SCM) represents an important evolution in the relationship practice among clients and suppliers belonging to a same distribution channel. This work presents a case study in an electrical-mechanical industry which the purpose is to investigate how the suppliers relationship are being incorporated to the strategic planning. The findings suggest that this actions with the suppliers brought gains in the several areas to the enterprise, but to it reaches a more high level of competitiviness also depends how are internal processes of the industry, mainly those related to discipline and the workers trainning, and the cultural alignment of all partners in the Supply Chain.
\end{abstract}

Key Words: supply chain management, supplier relationship management, logistics, lean thinking.

\title{
Referências
}

AZZOLINI JÚNIOR, W. Uma análise da evolução histórica da estrutura funcional do planejamento e controle da produção. Revista UNIARA, v. 9, p. 21-36, 2001.

BALLOU, R. H. Gerenciamento da cadeia de suprimentos: logística empresarial. $5^{\text {a }}$. Edição. Porto Alegre, Editora Bookman, 2006.

BOWERSOX, D. J.; CLOSS, D.J. Logística empresarial. São Paulo: Atlas, 2001.

CASTELlS, M. A sociedade em rede. v.1, 9. ed. São Paulo: Paz e Terra, 2006.

CHRISTOPHER, M. Logística e gerenciamento da cadeia de suprimentos: estratégias para a redução de custos e melhoria dos serviços. São Paulo: Thomson, 2002.

CSCMP. Council Supply Chain Management Professionals. Disponível em: <http://cscmp.org/aboutcscmp/definitions.asp>. Acesso em 14/01/2010. 
DAVIS, M.M. Fundamentos da Administração da Produção. Porto Alegre: Bookman, 2001.

FERNANDES, K.S. Logística: Fundamentos e Processos. Curitiba: IESD (Inteligência Educacional e Sistemas de Ensino) Brasil S.A, 2008.

FLEURY, P.F.; WANKE, P.; FIGUEIREDO K.F.; FOSSAT, K. Logística Empresarial: a perspectiva brasileira. São Paulo: Atlas, 2000.

LAMBERT, D.M. Supply Chain Management: Processes, Partnership, Performance. Supply Chain Management Inst., $3^{\text {rd }}$ Edition. Jacksonville: The Hartley Press, 2008.

MERLI, G. Comakership: a nova estratégia para os suprimentos. Rio de Janeiro: Qualitymark Ed., 1994.

MIGUEL, P.A.C. Metodologia de pesquisa em engenharia de produção e gestão. $1^{\text {a }}$. ed. São Paulo: Editora Campus, 2009.

OHNO, T. O Sistema Toyota de Produção: além da produção em larga escala; trad. Cristina Shumacher. Porto Alegre: Bookman, 1997.

PEREIRA, C.C.; SILVA, L.F. Capacitação de Fornecedores: o Programa Fit For Global Approach da Empresa Robert Bosch. Gestão \& Regionalidade - São Caetano do Sul - SP - Vol. 25 - No 74, pg 48-60 - mai-ago/2009.

PIRES, S.R.I. Gestão da cadeia de suprimentos (Supply Chain Management) - Conceitos, Estratégias e Casos. São Paulo: Ed. Atlas, 2004.

QUEIROZ, A.F.S.; PINTO, M.M.O; PEREIRA, S.C.F. Competências essenciais em uma rede de suprimentos naval: um estudo das práticas funcionais. Revista Gestão Industrial, v. 05, n. 03: p. 155-176, 2009.

cross ref

ROBESON, J. F.; COPACINO, W. C. The Logistics Handbook. New York: The Free Press, 1994.

SILVA, N.F.; GUIMARÃES I. F.G; PEREIRA, C. B.; FARIA, F.O.; OKANO, C.S.; FERREIRA, G.S. Análise do Sistema Toyota de Produção em duas empresas de ramos industriais distintos. XXVII ENEGEP. Foz do Iguaçu, PR, 2007.

VOLLMANN, T.E. Sistemas de planejamento e controle da produção para gerenciamento da cadeia de suprimentos. 5a . ed. Porto Alegre: Bookman, 2006.

WANKE, P.Uma revisão dos programas de resposta rápida: ECR, CRP, VMI, CPFR, JIT II. Disponível em: <www.centrodelogistica.2004.com.br/new/fs-public.htm>. Acesso em: 25 de janeiro de 2010.

WOMACK, J. A máquina que mudou o mundo. Rio de Janeiro: Ed. Campus, 2004.

WOMACK, J.; JONES, D. LeanThinking.New York: Free Press, 2003.

WOMACK, J.; JONES, D. A mentalidade enxuta nas empresas: elimine o desperdício e crie riqueza. Rio de Janeiro: Campus, 2004.

\section{Agradecimentos}

À CAPES - Coordenação de Aperfeiçoamento de Pessoal de Nível Superior pelo suporte financeiro.

\section{Dados dos autores:}

Nome completo: Marly Mizue Kaibara de Almeida

Filiação institucional: Universidade Estadual Paulista - Campus de Guaratinguetá - UNESP 
Departamento: Programa de Pós-graduação em Engenharia Mecânica

Função ou cargo ocupado: Doutoranda

Endereço completo para correspondência (bairro, cidade, estado, país e CEP): Rua Matias Peres, 364 - Ap.64 - Floradas de São José - São José dos Campos - SP - Brasil - CEP 12230-082

Telefones para contato: (12) 33072114

e-mail: mkalmeida28@hotmail.com

Nome completo: Fernando Augusto Silva Marins

Filiação institucional: Universidade Estadual Paulista - Faculdade de Engenharia do Campus de Guaratinguetá

Departamento: Produção

Função ou cargo ocupado: Professor Titular

Endereço completo para correspondência: DPD/FEG/UNESP, Av. Ariberto Pereira da Cunha, 333, CEP 12516-410 - Guaratinguetá - SP

Telefones para contato: (12) 31232866 (direto)/3123 2855 (secretária)

e-mail: fmarins@feg.unesp.br

Nome completo: Claudemir Leif Tramarico

Filiação institucional: Universidade Estadual Paulista - Faculdade de Engenharia do Campus de

Guaratinguetá

Departamento: Produção

Função ou cargo ocupado: Mestrando no Programa de Pós-graduação em Engenharia Mecânica

Endereço completo para correspondência: DPD/FEG/UNESP, Rua Tonelero, 214, CEP 05056-000

- São Paulo - SP

Telefones para contato: (11) 86311605

e-mail: claudemir.leif@terra.com.br

Recebido em: $14 / 08 / 2012$

Aceito em: 03/10/2012 